\title{
Are wolves welcome? Hunters' attitudes towards wolves in Vermont, USA
}

\author{
Nelson Grima, John Brainard and Brendan Fisher
}

\begin{abstract}
The forests of the north-east USA were once home to the wolf Canis lupus, a species that played an important role in the ecology of this region. However, wolves were eradicated from the region more than a century ago, altering the species composition of the landscape and driving cascading changes in this ecosystem. Outdoor recreation is a major component of the economy of this region, and outdoor recreationists, including the hunting community, have a strong influence over decision-making related to policies on natural resources. Given their powerful position, hunters are important stakeholders whose views need to be taken into account when designing policies related to wildlife, in particular in relation to a controversial species such as the wolf. In this study, through expert interviews and an online survey, we gained a deeper understanding of the attitudes of hunters towards wolves, and how these attitudes could affect any future reintroduction programme or natural movement of wolves into the state. We found that the majority of hunters hold a suite of negative attitudes towards wolves, their role in the landscape and their potential impact on the region. However, for hunters who were able to recognize the ecological roles of wolves, these negative attitudes were mostly reversed.
\end{abstract}

Keywords Attitudes, Canis lupus, expert interviews, hunting, opinion survey, Vermont, wolf reintroduction

Supplementary material for this article is available at https://doi.org/10.1017/So030605319000061

\section{Introduction}

7 he northeastern forests of the USA were once home to the wolf Canis lupus. This species played a key role in this ecosystem by providing trophic structure and stability through predator-prey dynamics, and probably had cascading influences on the composition and abundance of other taxa and on disease dynamics (Mech, 1995; Mladenoff \& Sickley, 1998; Ripple et al., 2014). However, from the 17th century until the 1970s in the USA, wolves were trapped,

Nelson Grima (Corresponding author, (D) orcid.org/0000-0001-5563-691X), JoHN BRAINARD and BRENDAN FisHeR (iD) orcid.org/0000-0001-6560-9093) Environmental Program, Rubenstein School for Environmental and Natural Resources, University of Vermont, 153 South Prospect St., Burlington, Vermont 05401, USA. E-mail nelson.grima@uvm.edu

Received 2 December 2018. Revision requested 14 January 2019.

Accepted 21 January 2019. First published online 30 October 2019. poisoned and shot from the ground and air without restrictions (Cluff \& Murray, 1995), and government agencies paid bounties for wolves killed (Musiani \& Paquet, 2004). In New England (the region comprising the states of Maine, Vermont, New Hampshire, Massachusetts, Connecticut and Rhode Island), wolves were eradicated through intense persecution more than a century ago (Feldhamer et al., 2003), with the last known record in the region being from 1887, in New Hampshire (Bodin, 2007).

The approval of the Endangered Species Act of 1973 framed the legal protection of wolves in the USA (Mladenoff \& Sickley, 1998), and in 1995 the wolf reintroduction programme in Yellowstone National Park became the focus of controversy, 'with ranchers fearing decimation of their stock by the reintroduced predators' (McKibben et al., 2000, p. 2). Ranchers threatened to shoot any wolf that inadvertently crossed the Yellowstone boundaries. Nevertheless, wolves were reintroduced in Yellowstone, providing opportunities for studies related to wolf-human interactions and coexistence in the USA (McKibben et al., 2000).

One focal area for such conflicts relates to how apex predators affect recreational opportunities. At national level, wildlife associated recreation activities (hunting, fishing and wildlife watching) generated USD 156.9 billion in 2016, including equipment, travel, licences and fees, and created thousands of jobs, particularly in rural areas (U.S. Fish \& Wildlife Service \& U.S. Census Bureau, 2018). In Vermont hunting is a key recreational activity that generates state conservation revenue, and its main season bridges an important revenue generation gap between the end of the autumn foliage tourist season and the beginning of the winter ski season (North East State Foresters Association, 2014). Hunting in Vermont includes the harvesting of white-tailed deer Odocoileus virginianus, moose Alces alces, black bear Ursus americanus and turkey Meleagris gallopavo. To a lesser extent, small game, upland game birds, and waterfowl are also hunted. Focusing on deer hunting, the 2017 season was highly successful, even with particularly difficult hunting conditions compared to previous years (Vermont Fish \& Wildlife Department, 2018). The deer population has been steadily increasing (in 2017, the total number of deer harvested was $13 \%$ higher than the previous 3-year mean, and the buck harvest was $8 \%$ higher than the previous 3-year mean), driving the department to increase the number of deer hunting permits, to control population growth (Vermont Fish \& Wildlife Department, 2018). 
In Vermont hunters have a strong influence on big game population control (without taking into account natural factors such as climate change or winter severity), and play an important role in the rural economy. Thus the hunting community is a key stakeholder in the development of wildlife related policies in Vermont, and the design of programmes related to the control or reintroduction of wildlife should take into account the hunting community's attitudes, to increase any programme's success. This is particularly critical if a potential programme aims to reintroduce a controversial species such as the wolf, or other large predator (for further discussion of this, see Mladenoff \& Sickley, 1998). However, hunters and other stakeholders should have factual and up-to-date information regarding the trade-offs of having particular species in the region. Here we therefore analyse information gathered through expert interviews and an online survey of the hunting community of Vermont, seeking to understand hunters' attitudes towards wolves in the state, including their attitudes to a hypothetical reintroduction of wolves, and investigating the underlying factors driving such attitudes. Following the definition of Newhouse (1990, p. 26), we use 'attitude' to mean 'an enduring positive or negative feeling about some person, object, or issue'.

\section{Methods}

We gathered information from the hunting community in Vermont through interviews and an online survey. The interviews were conducted in person during 1 March 20171 May 2017, and the online survey took place during 15 May 2017-31 July 2017. Expert interviews focus on the knowledge a person has as a result of his or her experiences, actions, responsibilities or obligations resulting from the person's status within an institution or organization. Expert interviews may follow a systematizing approach, based on the objective knowledge the expert has, or a theory-generating approach, based on the implicit knowledge the expert has because of his or her actions and interpretations (Litting, 2011). In this study we combined both approaches, to obtain a broad view of the topic. As the research team defines who qualifies as an expert (Litting, 2011), we identified the hunting community in Vermont as experts.

Using Treves \& Martin (2011), we defined a set of questions aiming to facilitate expert interviews. By means of personal contacts we arranged 12 interviews with hunters from the towns of Burlington, Charlotte, Hinesburg, South Burlington and Williston, in Vermont. The results of these interviews were used to gauge the general positions of hunters, and thus to develop an informed questionnaire for the implementation of the online survey. From analysis of the interviews we focused on recurring themes, and used these to design the questionnaire (Supplementary Material 1).
To make the questionnaires available, we used the online tool Lime Survey (LimeSurvey Project Team, 2012). This is a free and open-source application that enables users to develop and publish online surveys, collect responses, create statistics and export the resulting data. After creating the questionnaire, we piloted it, and shortened it to ensure it could be clearly understood and completed in less than 5 minutes. Creating an online survey with Lime Survey generates a link that can be shared online. We posted this link on a number of blog sites and other social media sites created or used by the hunting community in Vermont. There is no minimum age for hunting in Vermont; the only age requirement is that a person under age 16 must have a parent or guardian sign to obtain a hunting licence (Vermont Hunting, 2018). We therefore excluded responses from hunters $<18$ years old. We compiled the answers and used descriptive statistics to investigate the hunting community's attitudes towards and knowledge of wolves in Vermont.

To investigate whether the hunters' knowledge of wolf ecology had an influence over their attitudes towards wolves, we ran an additional statistical analysis. As hunters provided their opinion on the statement 'Wolves keep deer herds healthy by killing the sick and weak animals', and because this statement has an ecological basis (e.g. Wright et al., 2006; Mech, 2007; Mitchell et al., 2015), we examined whether there was a correlation between the number of hunters who disagreed with this statement and the hunters with negative perception towards wolves, using a Pearson's $\chi^{2}$ test with Yates' continuity correction (Yates, 1934), in $R$ 3.5.o (R Core Team, 2017), which evaluates the likelihood that differences between two sets of data are a result of chance (Gosall \& Gosall, 2012).

\section{Results}

Although we received a total of 204 responses to the online survey, only 151 of the questionnaires were from hunters $\geq 18$ years old, and were sufficiently complete for analysis. In some questionnaires received, hunters left 1-2 questions unanswered. Questionnaires in which hunters only answered the demographic section were not included in the analysis.

The average hunter participating in this survey was a 41 year old male who had been hunting for 27 years. Age range was $18-76$ years, $6 \%$ were female (of the 136 participants who disclosed their gender), and respondents had been hunting for 2-62 years. The majority of hunters $(57 \%)$ had negative attitudes towards wolves, $28.5 \%$ had a positive attitude, and $14.6 \%$ did not state their opinion (Fig. 1). When asked whether wolves should be reintroduced into Vermont, $76.1 \%$ of the participants were against this (Fig. 2).

When asked if they saw any advantage in wolves returning to Vermont, $79.5 \%$ saw no advantage and only $17.9 \%$ saw advantages. As an addition to this question, hunters were 


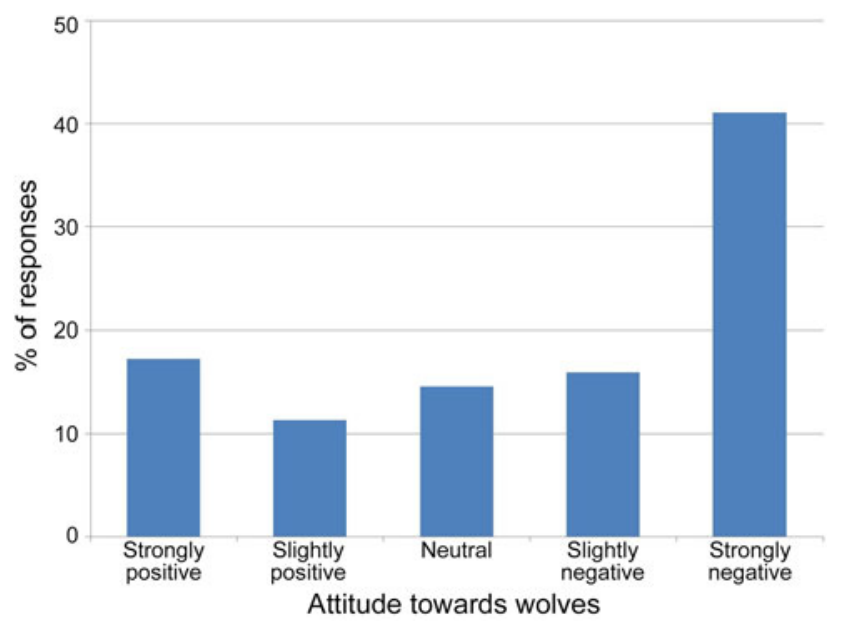

Fig. 1 Per cent responses of 151 hunters to the question exploring attitudes towards wolves.

asked to expand on their answers and detail any arguments for and against wolves returning to Vermont. The arguments supportive of reintroduction were: (1) wolves were once native to the region, (2) wolves would restore a naturally balanced ecosystem, (3) wolves would control other predators, and (4) wolves would improve hunting opportunities (Table 1). Arguments against wolves returning fell into seven categories (plus 'others', for statements we could not categorize): (1) risks involved in interactions with humans, pets and livestock, (2) pressure on deer and other game, (3) inadequate habitat for wolves, (4) mixed pressures on game and livestock, (5) reflections on reintroduction experiences in other regions, (6) wolves as vicious killers and a danger in general, (7) there are enough predators already (mainly referring to the coyote Canis latrans), and (8) others (Table 1).

At the end of the questionnaire, the hunters were asked to provide their level of agreement to a set of predefined statements. More than three quarters $(76.1 \%$ combining 'disagreement' and 'strong disagreement') of participants were against having wolves in Vermont. Most hunters (75.5\%) believed that wolves would threaten deer hunting opportunities, and that they belong in a place such as the state of Alaska but not in Vermont (55\%). In general, participants did not see wolves as positively affecting deer herds by keeping them healthy (59\%) or maintaining the ecological balance $(63.6 \%)$. But almost half of participants $(45 \%)$ believed that wolves regulate populations of other predators such as the coyote. Initially, $76.2 \%$ of hunters were opposed to wolf reintroduction but the percentage diminished to $60.3 \%$ if compensation was provided for damages, and to $49 \%$ if the hunting of wolves was allowed. One third of participants $(33.1 \%)$ declared they would be afraid if wolves lived near their homes, and $52.3 \%$ acknowledged they would be afraid for the safety of others. Surprisingly, despite the

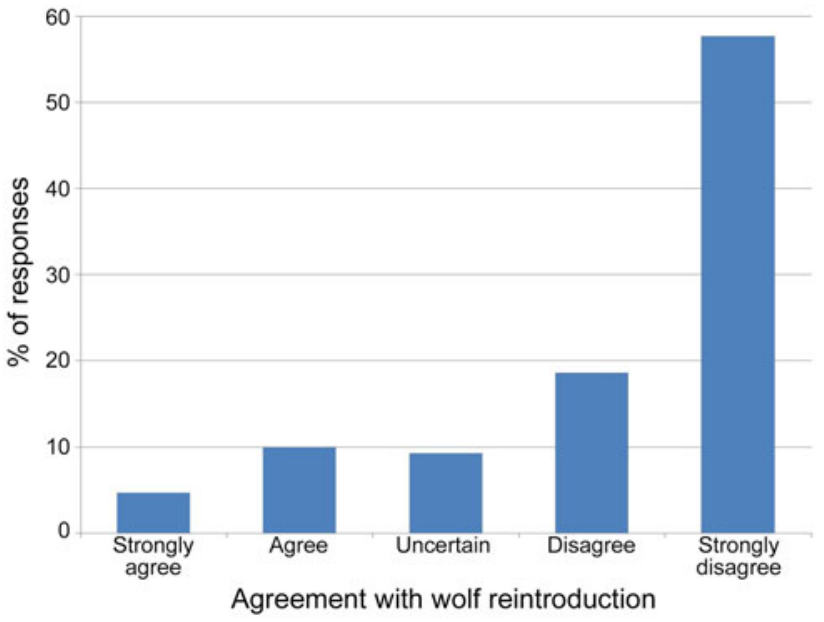

FIG. 2 Per cent responses of 151 hunters to the question asking whether wolves should be reintroduced into Vermont.

TABLE 1 Arguments for and against a potential reintroduction of wolves Canis lupus into Vermont.

\section{Arguments for a reintroduction}

(1) Wolves were once native to the region (6 statements)

(2) Reintroducing wolves would restore a naturally balanced ecosystem (7 statements)

(3) Wolves would control other predators (11 statements)

(4) Wolves would improve hunting opportunities (6 statements) Arguments against a reintroduction

(1) Risks involved in wolf interactions with humans, pets \& livestock (8 statements)

(2) Pressure on deer \& other game (46 statements)

(3) No adequate habitat for wolves (27 statements)

(4) Mixed pressures on game \& livestock (18 statements)

(5) Reflecting on previous reintroduction experiences in other regions (4 statements)

(6) Wolves are vicious killers \& a danger in general (8 statements)

(7) There are enough predators already (6 statements)

(8) Others:

'This is not needed.'

'This survey is clearly an attempt at limiting deer hunting in

Vermont. This is why the deer hunting question was asked. I've heard gun control advocates argue bringing wolves to Vermont so we won't have to have a deer season.'

'Viable habitat public opposition funding/regulation issues.

Current game population goals of state agencies.'

general negative attitudes towards wolves, nearly half of the participants admitted that seeing a wolf in the wild would be one of the greatest outdoor experiences of their lives (43.1\% agreed with the statement, $37.1 \%$ disagreed; Table 2). The Pearson's $\chi^{2}$ test indicated a positive correlation between knowledge of wolves and attitudes $\left(\chi^{2}=39.2596, \mathrm{P}<0.001\right.$ ); i.e. having inaccurate (or no) knowledge of wolf ecology correlated with negative attitudes towards wolves. 
TABLE 2 The degree of agreement of 151 hunters to 11 predefined statements regarding wolves and hunting.

\begin{tabular}{|c|c|c|c|c|c|c|}
\hline & $\begin{array}{l}\text { Strongly } \\
\text { agree } \\
\mathrm{n}(\%)\end{array}$ & $\begin{array}{l}\text { Agree } \\
\mathrm{n}(\%)\end{array}$ & $\begin{array}{l}\text { Uncertain } \\
\mathrm{n}(\%)\end{array}$ & $\begin{array}{l}\text { Disagree } \\
\mathrm{n}(\%)\end{array}$ & $\begin{array}{l}\text { Strongly } \\
\text { disagree } \\
\mathrm{n}(\%)\end{array}$ & $\begin{array}{l}\text { No } \\
\text { answer } \\
\mathrm{n}(\%)\end{array}$ \\
\hline Wolves should be reintroduced into Vermont. & $7(4.6)$ & $15(9.9)$ & $14(9.3)$ & $28(18.5)$ & $87(57.6)$ & $0(0)$ \\
\hline $\begin{array}{l}\text { Reintroducing wolves into Vermont threatens deer hunting } \\
\text { opportunities. }\end{array}$ & $82(54.3)$ & $32(21.2)$ & $17(11.3)$ & $12(7.9)$ & $8(5.3)$ & $0(0)$ \\
\hline $\begin{array}{l}\text { My tolerance of reintroducing wolves would increase if } \\
\text { people could hunt them. }\end{array}$ & $17(11.3)$ & $24(15.9)$ & $27(17.9)$ & $34(22.5)$ & $45(29.8)$ & $4(2.6)$ \\
\hline $\begin{array}{l}\text { Wolves keep deer herds healthy by killing the sick \& weak } \\
\text { animals. }\end{array}$ & $10(6.6)$ & $36(23.8)$ & $16(10.6)$ & $33(21.9)$ & $56(37.1)$ & $0(0)$ \\
\hline Wolves keep populations of other predators in check. & $18(11.9)$ & $50(33.1)$ & $30(19.9)$ & $18(11.9)$ & $29(19.2)$ & $6(4.0)$ \\
\hline I would be afraid if wolves lived near my home. & $21(13.9)$ & $29(19.2)$ & $23(15.2)$ & $49(32.5)$ & $24(15.9)$ & $5(3.3)$ \\
\hline $\begin{array}{l}\text { I would be afraid for the safety of others if wolves were } \\
\text { reintroduced. }\end{array}$ & $35(23.2)$ & $44(29.1)$ & $19(12.6)$ & $35(23.2)$ & $17(11.3)$ & $1(0.7)$ \\
\hline $\begin{array}{l}\text { My tolerance of wolves would increase if compensations } \\
\text { were given for damages caused by wolves. }\end{array}$ & $4(2.6)$ & $20(13.2)$ & $16(10.6)$ & $40(26.5)$ & $63(41.7)$ & $8(5.3)$ \\
\hline Wolves are essential for maintaining the balance of nature. & $11(7.3)$ & $21(13.9)$ & $18(11.9)$ & $45(29.8)$ & $51(33.8)$ & $5(3.3)$ \\
\hline Wolves belong in a place like Alaska, not Vermont. & $35(23.2)$ & $48(31.8)$ & $25(16.6)$ & $23(15.2)$ & $15(9.9)$ & $5(3.3)$ \\
\hline $\begin{array}{l}\text { Seeing a wolf in the wild would be one of the greatest } \\
\text { outdoor experiences of my life. }\end{array}$ & $24(15.9)$ & $41(27.2)$ & $26(17.2)$ & $27(17.9)$ & $29(19.2)$ & $4(2.6)$ \\
\hline
\end{tabular}

\section{Discussion}

In our questionnaire survey, which was developed based on previous studies and expert interviews, we sought to investigate the attitudes of hunters towards wolves and the potential reintroduction of this species to Vermont. As expected, the results showed that, in general, the attitudes of hunters towards wolves are negative. Our analysis also shows that some of the reasons for these negative attitudes are based on misconceptions or inaccurate knowledge and information. Thus, we posit that programmes aiming to educate and provide information related to wolf ecology, to hunters, and to the public in general, could have a positive effect on how hunters and the general public perceive wolves and their potential presence in Vermont. In other regions of the country some organizations are already taking this approach by providing a more objective view of wolf behaviour rather than by conveying value judgements (i.e. not by portraying wolves as either good or bad). For example, schools and public libraries in Minnesota have free access to the course Wolves at Our Door, which covers, among other topics, wolf biology and behaviour (International Wolf Center, 2018). Other examples are the U.S. Fish \& Wildlife Service website with wolf facts and links to further information (U.S. Fish \& Wildlife Service, 2018), NGOs providing online information and being active on social media (e.g. International Wolf Center, 2018), and reports published by scholars and conservation practitioners (National Park Service, 2018). Writers, songwriters and illustrators are also changing the narratives of their stories, publishing works that avoid criminalizing wolves (e.g. Kotrschal \& Benedetter-Herramhof, 2017).
Most of the hunters we surveyed did not acknowledge the important role that wolves play in ecosystems; for instance, most participants disagreed that wolves limit the population of coyotes in places where they co-occur. A main concern for hunters participating in this study was that the presence of wolves would limit hunting. In similar ecological conditions, in the Superior National Forest in Minnesota, a wolf kills on average 18 deer per year, and 15 if wolves have access to other prey such as beaver Castor canadensis (Mech \& Karns, 1977). The estimated area of potential wolf habitat in Vermont is $6,036 \mathrm{~km}^{2}$ (Mladenoff \& Sickley, 1998; research is required to update this estimate), occurring primarily along the Green Mountains in the centre of the state and the forests on the north-east border with New Hampshire. This area could support a potential wolf population of 62 individuals (Mladenoff \& Sickley, 1998), which could potentially predate 1,116 deer annually. This is $<7 \%$ of the total 15,984 deer harvested by hunters in 2017 , a year marked by particularly difficult hunting conditions (Vermont Fish \& Wildlife Department, 2018).

Most participants expressed concern for the personal safety of others, rather than for themselves, in the presence of wolves. Focusing on wild, unhabituated wolves (i.e. excluding captive wolves and those used to human presence), we searched for records of wolf interactions with people since 1900, in the USA and Canada (in Canada tens of thousands of wolves coexist with humans). In the last 118 years, 27 predatory attacks and close encounters were registered (c. 1 attack every 4.5 years), with a total of 25 people injured or stalked, and two people killed (Linnell et al., 2002; McNay, 2007; Butler et al., 2011; diverse news agencies). In addition there were 10 attacks ( 2 fatal) by 
rabid or otherwise sick wolves in the same period, showing that such attacks are rare (Linnell et al., 2002; diverse news agencies). For context, a mean of c. 5 million people are attacked by domestic dogs and cats annually in the USA, and in 2018 alone 36 people were killed by domestic dogs (Baddour \& Harper, 2018). Regarding attacks by other large wild animals in the USA and Canada, and focusing only on fatal attacks, various news agencies reported 25 people killed by bears (black, brown Ursus arctos and polar Ursus maritimus) since 2010, and 16 people killed by cougars Puma concolor since 1970. Thus, although wolf attacks on people are infrequent in comparison to deaths from other animals, the responses of the hunters in our survey suggests that conservation planning for wolves needs to consider fear of wolves as a significant concern.

Although some studies have identified Vermont as suitable for wolves (e.g. Mladenoff \& Sickley, 1998), other studies only recognized limited suitability as wolf habitat (e.g. Harrison \& Chapin, 1997, 1998; Carroll, 2003, 2005). Nevertheless, wolves can move great distances in search of new territory (e.g. Wabakken et al., 2007; Ciucci et al., 2009; Treves et al., 2009), and it is likely that wolves will at some time move into Vermont from other states or from eastern Canada. Our study and similar research can help prepare for the avoidance of conflicts.

In summary, our findings indicate that (1) most hunters in Vermont have a negative attitude towards wolves but that their tolerance could increase if they were allowed to hunt them, (2) approximately half of the surveyed hunters expressed safety concerns arising from the potential presence of wolves, but largely for the safety of other people, and (3) although some hunters have knowledge of the ecological role of the wolf, many (predominantly hunters with the most negative attitudes) provided statements that contradicted the scientific literature. Based on these findings, and following Musiani \& Paquet (2004, p. 1) that 'history has demonstrated that societal values ultimately determine the survival of species such as the wolf, we argue that outreach and education efforts are needed to communicate information to the hunting community, showing the most recent statistics and enhancing knowledge of wolf behaviour. Comparisons with regions where wolves have established successful populations (either by reintroduction or by natural dispersal) could be helpful to increase the awareness of the role wolves play in natural ecosystems and in the socio-economic context.

Acknowledgements We thank Adrian Treves for sharing his knowledge, the Vermont Fish \& Wildlife Department staff for providing information and literature, and the Vermont hunting community for taking the time to complete the online surveys.

Author contributions All authors contributed equally.

Conflicts of interest None.
Ethical standards This research abided by the Oryx guidelines on ethical standards, did not involve experimentation with animals and/ or collection of specimens, and is covered under UVM IRB CHRBSS 16-526 institutional ethical clearance from the University of Vermont.

\section{References}

Baddour, L.M. \& Harper, M. (2018) Patient education: animal and human bites (Beyond the Basics). UpToDate, Https://www. uptodate.com/contents/animal-and-human-bites-beyond-thebasics [accessed 9 July 2018].

Bodin, M. (2007) Waiting for Wolves. Https://northernwoodlands. org/outside_story/article/waiting_for_wolves [accessed 9 July 2018].

Butler, L., Dale, B., Beckmen, K. \& Farley, S. (2011) Findings Related to the March 2010 Fatal Wolf Attack Near Chignik Lake, Alaska. Alaska Department of Fish and Game, Fairbanks, USA.

CARROLL, C. (2003) Impacts of landscape change on wolf viability in the northeastern US and southeastern Canada: implications for wolf recovery. Wildlands Project Special Paper, 5.

CARroll, C. (2005) Carnivore restoration in the Northeastern US and Southeastern Canada: a regional-scale analysis of habitat and population viability for wolf, lynx, and marten (Report 2: Lynx and marten viability analysis). Wildlands Project Special Paper, 6.

Ciucci, P., Reggioni, W., Maiorano, L. \& Boitani, L. (2009) Longdistance dispersal of a rescued wolf from the northern Apennines to the Western Alps. Journal of Wildlife Management, 73, 1300-1306.

Cluff, H.D. \& Murray, D.L. (1995) Review of wolf control methods in North America. In Ecology and Conservation of Wolves in a Changing World (eds L.N. Carbyn, S.H. Fritts \& D.R. Seip), pp. 491-607. University of Alberta, Canadian Circumpolar Institute, Edmonton, Canada.

Feldhamer, G.A., Thompson, B.C. \& Chapman, J.A. (2003) Wild Mammals of North America: Biology, Management, and Conservation. John Hopkins University Press, Baltimore, USA.

Gosall, N.K. \& Gosall, G.S. (2012) The Doctor's Guide to Critical Appraisal. PasTest Ltd, Knutsford, UK.

Harrison, D.J. \& Chapin, T.G. (1997) An Assessment of Potential Habitat for Eastern Timber Wolves in the Northeastern United States and Connectivity with Occupied Habitat in Southeastern Canada: a Summary Report and Position Paper. Wildlife Conservation Society, New York, USA.

Harrison, D.J. \& Chapin, T.G. (1998) Extent and connectivity of habitat for wolves in eastern North America. Wildlife Society Bulletin (1973-2006), 26, 767-775.

International Wolf Center (2018) Wolves at Our Door. Https:// www.wolf.org/programs/wolves-at-our-door [accessed 12 July 2018].

Kotrschal, K. \& Benedetter-Herramhof, A. (2017) Vom Wilden Wolf zum Treuen Freund: Unsere Hunde. 1st edition. Herramhof Verlag, St Florian, Austria.

LimeSurvey Project Team (2012) LimeSurvey: an Open Source Survey Tool. LimeSurvey Project, Hamburg, Germany. Http://www. limesurvey.org [accessed 5 September 2019].

Linnell, J., Andersen, R., Andersone, Z., Balciauskas, L., Blanco, J., Boltani, L. et al. (2002) The Fear of Wolves: a Review of Wolf Attacks on Humans. NINA, Norsk Institutt for Naturforskning, Trondheim, Norway.

LitTing, B. (2011) Interviews, expert. In International Encyclopedia of Political Science (eds B. Badie, D. Berg-Schlosser \& L. Morlino), pp. 1343-1346. Sage, London, UK, Thousand Oaks, USA and New Delhi, India.

McKibben, B., DeBoer, K., Theberge, J. \& Bass, R. (2000) The Return of the Wolf: Reflections on the Future of Wolves in the Northeast. University Press of New England, Hanover, USA. 
McNay, M.E. (2007) A Review of Evidence and Findings Related to the Death of Kenton Carnegie on 8 November 2005 Near Points North, Saskatchewan. Alaska Department of Fish and Game, Fairbanks, USA.

MECH, L.D. (1995) The challenge and opportunity of recovering wolf populations. Conservation Biology, 9, 270-278.

$\mathrm{MeCH}$, L.D. (2007) Femur-marrow fat of white-tailed deer fawns killed by wolves. Journal of Wildlife Management, 71, 920-923.

MeCH, L.D. \& Karns, P.D. (1977) Role of the Wolf in a Deer Decline in the Superior National Forest. US Department of Agriculture, Forest Service, North Central Forest Experiment Station, St Paul, USA.

Mitchell, C.D., Chaney, R., Aho, K., Kie, J.G. \& Bowyer, R.T. (2015) Population density of Dall's sheep in Alaska: effects of predator harvest? Mammal Research, 60, 21-28.

MladenofF, D.J. \& SiCKLEY, T.A. (1998) Assessing potential gray wolf restoration in the Northeastern United States: a spatial prediction of favorable habitat and potential population levels. The Journal of Wildlife Management, 62, 1-10.

Musiani, M. \& Paquet, P.C. (2004) The practices of wolf persecution, protection, and restoration in Canada and the United States. BioScience, 54, 50-60.

National Park Service (2018) Yellowstone Wolf Project Reports. Https://www.nps.gov/yell/learn/nature/wolfreports.htm [accessed 12 July 2018].

Newhouse, Nancy (1990) Implications of attitude and behaviour research for environmental conservation. The Journal of Environmental Education, 22, 26-32.

North East State Foresters Association (2014) The Economic Importance of Vermont's Forest-Based Economy 2013. State of Vermont, USA.

R Core TeAm (2017) R: a Language and Environment for Statistical Computing. R Foundation for Statistical Computing, Vienna, Austria.
Ripple, W.J., Estes, J.A., Beschta, R.L., Wilmers, C.C., Ritchie, E.G., Hebblewhite, M. et al. (2014) Status and ecological effects of the world's largest carnivores. Science, 343, 1241484.

Treves, A. \& Martin, K.A. (2011) Hunters as stewards of wolves in Wisconsin and the northern Rocky Mountains, USA. Society \& Natural Resources, 24, 984-994.

Treves, A., Martin, K.A., Wiedenhoeft, J.E. \& Wydeven, A.P. (2009) Dispersal of gray wolves in the great lakes region. In Recovery of Gray Wolves in the Great Lakes Region of the United States (eds A.P. Wydeven, T.R. van Deelen \& E. Heske), pp. 191-204. Springer-Verlag, New York, USA.

U.S. Fish \& Wildlife Service \& U.S. Census Bureau (2018) 2016 National Survey of Fishing, Hunting, and Wildlife-Associated Recreation. Https://wsfrprograms.fws.gov/subpages/nationalsurvey/ nat_survey2016.pdf [accessed 9 July 2019].

U.S. Fish \& Wildlife Service (2018) Conserving the Nature of America. Https://fws.gov/midwest/wolf/aboutwolves/biologue.htm [accessed 12 July 2018].

Vermont Fish \& Wildifie Department (2018) 2017 Vermont Wildlife Harvest Report - Deer. Agency of Natural Resources, Montpelier, USA.

VERMONT HUNTING (2018) License Information. Http://www.eregulations. $\mathrm{com} /$ vermont/hunting/license-information [accessed 12 July 2018].

Wabakken, P., Sand, H., Kojola, I., Zimmermann, B., Arnemo, J. M., Pedersen, H. \& Liberg, O. (2007) Multistage, long-range natal dispersal by a global positioning system-collared Scandinavian wolf. Journal of Wildlife Management, 71, 1631-1634.

Wright, G.J., Peterson, R.O., Smith, D.W. \& Lemke, T.O. (2006) Selection of Northern Yellowstone Elk by gray wolves and hunters. Journal of Wildlife Management, 70, 1070-1078.

YATES, F. (1934) Contingency tables involving small numbers and the $\chi^{2}$ test. Supplement to the Journal of the Royal Statistical Society, $1,217-235$. 